EDITORIAL

\title{
Impact of health care initiatives on outcomes of acute coronary syndromes
}

\author{
M Moscucci, D Share
}

Heart 2006;92:293-295. doi: 10.1136/hrt.2004.058305

\begin{abstract}
Assessing efforts to apply clinical guidelines in community practice, with the goal of improving the quality and outcomes of care, presents many challenges
\end{abstract}

just providing feedback to physicians and institutions on the use of quality indicators could improve guideline adherence and could ultimately improve patients' outcomes. ${ }^{7}$ In that study, data collection at baseline was followed by a repeat sampling subsequent to an intervention which included data feedback. At follow up, significantly higher rates of aspirin use during the same hospitalisation and of $\beta$ blocker use upon discharge were observed after the intervention. These improvements in key measures of care processes were associated with a reduction in 30 day and one year mortality. patients with acute coronary syndromes.

Unfortunately, despite compelling data on the effectiveness of $\beta$ blockers, aspirin, angiotensin converting enzyme (ACE) inhibitors, and statins in reducing cardiovascular morbidity and mortality when used in the context of acute coronary syndromes, and the data on the importance of early reperfusion in patients with acute myocardial infarction, substantial practice variation exists, and underutilisation of these evidence based treatments has been well documented in many observational studies. ${ }^{1-4}$ In 1992, the Health Care Financing Administration initiated the National Cardiovascular Cooperative Project (NCCP) in the USA. The aim of that project was to improve quality of care for patients with coronary artery disease. The staggering finding of the initial analysis included a substantial underutilisation of $\beta$ blockers, ACE inhibitors, and aspirin in patients who did not have any contraindication to the use of these treatments. ${ }^{1}$

\section{CLINICAL GUIDELINES}

The development of clinical guidelines by national and international societies has helped by providing practising physicians with simplified tools to support incorporating lessons learned from clinical trials into clinical practice on a routine basis. ${ }^{56}$ However, more recent studies have shown an absence of a temporal relationship between the publication of guidelines and improved incorporation of treatment recommendations in hospital practice for patients with acute coronary syndromes. ${ }^{3}$ The same studies have suggested that local and national circumstances, including whether care is provided in teaching centres, availability of resources, and healthcare policies, have an important role in the incorporation of evidence based treatments in clinical practice. Thus, clinical guidelines alone seem to be not sufficient to bridge the gap between clinical trials and clinical practice.

Three years after the initial report of the NCCP, findings from a follow up study suggested that

\section{AGGRESSIVE INTERVENTIONS}

Although data feedback may influence practice sufficiently to improve adherence to quality indicators, and ultimately clinical outcomes, recent studies have suggested that more aggressive interventions might result in substantially greater improvement of the quality of care. Soumerai et $a l^{8}$ randomised hospitals to either simple performance feedback mailed to clinical leaders, or to a systematic intervention including: the identification of opinion leaders charged with the responsibility to influence their peers through small and large group discussions; provision of informal consultation; revision of hospital protocols and clinical pathways; distribution of comparative performance reports; and identification of barriers to change in approaches to care for patients with acute myocardial infarction. A higher increase in utilisation of aspirin and $\beta$ blockers was observed in the intervention group when compared to the control group.

A similar approach was used in the more recent guidelines applied in practice (GAP) study. This regional intervention intended to improve quality of care for patients with acute coronary syndromes; it included hospital site visits by project leaders serving as cardiac care experts, the development of standing orders and tool kits, simple hospital discharge contracts designed to ensure that patients left the hospital having received essential medications, advice and education, and systematic data feedback on performance on key quality indicators. ${ }^{9}$ The project goal was to assure systematic provision of essential services to patients with acute

Abbreviations: $A C E$, angiotensin converting enzyme; CMMS, Centers for Medicare and Medicaid; GAP, guidelines applied in practice; JCAHO, Joint Commission on Accreditation of Healthcare Organizations; NCCP, National Cardiovascular Cooperative Project; NSF, National Service Framework; P4P, Pay for Performance

0311, USA; moscucci@ umich.edu 
coronary syndromes. This effort was shown to result in significant improvement in quality of care in the 10 intervention hospitals when compared to a group of 11 control hospitals that were not selected for participation. In addition, more recently, the same group has published data supporting an association between the intervention performed and a reduction in 30 day and one year mortality for patients with myocardial infarction. ${ }^{10}$

\section{NATIONAL SERVICE FRAMEWORK}

Similar to the NCCP, the UK instituted the National Service Framework (NSF) for coronary heart disease in March 2000 (http://www.nelh.nhs.uk/nsf/). This was the beginning of a government led initiative aimed at improving the quality of care for patients with coronary artery disease. The project set the ambitious goal of reducing mortality from coronary artery disease by $40 \%$ by the year 2010, and of standardising treatment and ending geographical variations through the country. In a recent study providing the first report examining the impact of the NSF for coronary heart disease on emergency treatment, quality indicators, and outcomes in patients presenting with acute coronary syndromes, data collected before institution of the NSF were compared to data collected after its implementation. ${ }^{11}$ The authors found that after the NSF became operational there was an increase in the use of $\beta$ blockers, ACE inhibitors, and statins, and an increase in the proportion of patients referred for invasive investigation. In addition, there was a significant reduction in time to treatment in patients receiving thrombolysis. These changes were associated with reduced rates of new $\mathrm{Q}$ waves on the ECG, congestive heart failure during the same hospitalisation, and in-hospital mortality. While the observational nonrandomised design represents an important limitation in the study design, and while the increase in the use of some evidence based treatments appeared to be due to temporal trends rather than to the implementation of the NSF ( $\beta$ blockers and statins), the authors, with a detailed analysis, were able to support the hypothesis that the improvement in the overall quality of care might had been directly (at least in part) related to implementation of the NSF.

\section{THIRD PARTY PAYERS}

In parallel with the advances in understanding of optimal therapeutic options for patients with acute coronary syndromes, the increasing awareness of the gap between optimal care and actual care, and significant escalation in health care costs, have led third party payers in the USA to ask health care providers to demonstrate the quality of their care, and to improve its efficiency. These changes have led to a new movement promoting what is now commonly called "Pay for Performance" (P4P). The Centers for Medicare and Medicaid's (CMMS) Medicare programme has instituted an incentive for public reporting of performance on key quality indicators (http://www.cms.hhs.gov/media/press/release.asp? Counter $=1343$ ), including measures pertaining to the care of patients with acute myocardial infarction and heart failure. ${ }^{12}$ This incentive comes in the form of a $0.4 \%$ reduction in Medicare payment for inpatient services for hospitals which fail to report performance on these quality indicators to the government, which then posts them on its Hospital Compare website (www.hospitalcompare.hhs.gov/). The Joint Commission on Accreditation of Healthcare Organizations (JCAHO) has joined with CMMS in the adoption of these uniform quality indicators, which JCAHO calls core indicators. Non-governmental third party payers have incorporated these same measures into their own P4P programmes and also undertake efforts to inform their members of comparative performance of hospitals in their networks. The role of public reporting of outcome data for

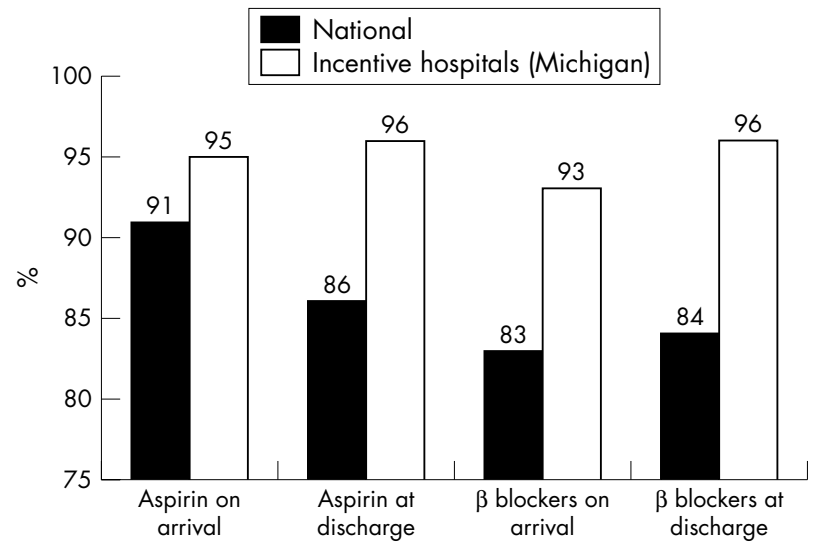

Figure 1 Comparison of rates of administration of $\beta$ blockers and aspirin in patients with acute myocardial infarction in 2004. The solid bars represent the national bench mark and the open bars represent Michigan hospitals with incentive.

procedures, including coronary artery bypass surgery and percutaneous coronary intervention, is currently controversial. ${ }^{13}{ }^{14}$ Some studies suggest a potential unintended effect resulting in denial of care to high risk patients, and in particular to patients with cardiogenic shock or acute myocardial infarction. ${ }^{13}$ Nevertheless, it is conceivable that public reporting of quality indicators for acute coronary syndromes will provide a driving force for efforts intended to ultimately improve adherence to those indicators.

In one such statewide effort (Blue Cross Blue Shield of Michigan's Participating Hospital Agreement Incentive Program), sustained improvements in these measures have been observed with hospitals accountable for performance on these measures. This effort has shown that hospitals in the state of Michigan accountable for performance on these measures had consistently higher performance than national benchmarks (fig 1).

While these results are encouraging, and while we know that improved performance on these measures may lead to improved outcomes, it is important to note that such P4P programmes only address a narrow range of aspects of health care quality which represent those processes for which incontrovertible, objective evidence exists to support their universal adoption. Yet, much of cardiac care falls under the heading of care which is highly technical, rapidly evolving and regarding which scientific uncertainty exists (for example, the arena of percutaneous coronary intervention for patients with acute coronary syndromes). These vast areas of cardiac care are not best addressed through means such as used in the NSF, GAP, or NCCP. Rather, opportunities to better understand optimal practice and widely disseminate such knowledge should be acted on in the context of collaborative, inter-institutional, clinical-data-registry-driven, continuous quality improvement projects. ${ }^{15}{ }^{16}$

\section{IMPROVING OUTCOMES OF CARE}

All that said, the assessment of efforts to apply clinical guidelines in community practice with the goal of improving the quality and outcomes of care presents many challenges. These include the evaluation of the effect of temporal trends, and teasing out the relative impact of such temporal trends and the true effects of quality improvement interventions on observed improvements in practice. As efforts to improve the quality of care themselves become more sophisticated in the methods they employ, randomised clinical trials will be increasingly employed to evaluate quality improvement interventions systematically. Yet, even with such randomised 
clinical trials there will be important challenges to be addressed, including issues surrounding sample size when the randomisation occurs at a facility level, and the risk of cross contamination across the randomisation arms. For example, just agreeing to participate in a quality improvement intervention might itself represent a selection bias as a marker of a significant motivation toward making internal changes in the process of care, despite randomisation to the "non-intervention" or "control" arm. In the meantime, observational comparison studies continue to be the best means of evaluating the effectiveness of systematic implementations of clinical guidelines and of large scale (for example, regional or national quality) improvement programmes on quality indicators and clinical outcomes of acute coronary syndromes.

\section{Authors' affiliations}

M Moscucci, The University of Michigan, Division of Cardiology, Ann Arbor, Michigan, USA

D Share, The Center for Health Care Quality and Evaluative Studies Blue Cross and Blue Shield of Michigan, Detroit, Michigan, USA

\section{REFERENCES}

1 Ellerbeck EF, Jencks SF, Radford MJ, et al. Quality of care for Medicare patients with acute myocardial infarction. A four-state pilot study from the cooperative cardiovascular project. JAMA 1995;273:1509-14.

2 Rogers WJ, Bowlby $\sqcup$, Chandra NC, et al. Treatment of myocardial infarction in the United States (1990 to 1993). Observations from the national registry of myocardial infarction. Circulation 1994;90:2103-14.

3 Fox KA, Goodman SG, Anderson FA Jr, et al. From guidelines to clinical practice: the impact of hospital and geographical characteristics on temporal trends in the management of acute coronary syndromes. The global registry of acute coronary events (GRACE). Eur Heart J 2003;24:1414-24.

4 Fox KA, Goodman SG, Klein W, et al. Management of acute coronary syndromes. Variations in practice and outcome; findings from the global registry of acute coronary events (GRACE). Eur Heart J 2002;23:1177-89.
5 Antman EM, Anbe DT, Armstrong PW, et al. ACC/AHA guidelines for the management of patients with ST-elevation myocardial infarction; a report of the American College of Cardiology/American Heart Association task force on practice guidelines (committee to revise the 1999 guidelines for the management of patients with acute myocardial infarction). J Am Coll Cardiol 2004;44:E1-211.

6 Braunwald E, Antman EM, Beasley JW, et al. ACC/AHA guidelines for the management of patients with unstable angina and non-ST-segment elevation myocardial infarction. A report of the American College of Cardiology/ American Heart Association task force on practice guidelines (committee on the management of patients with unstable angina). J Am Coll Cardiol 2000;36:970-1062.

7 Marciniak TA, Ellerbeck EF, Radford MJ, et al. Improving the quality of care for Medicare patients with acute myocardial infarction: results from the cooperative cardiovascular project. JAMA 1998;279:1351-7.

8 Soumerai SB, McLaughlin TJ, Gurwitz JH, et al. Effect of local medical opinion leaders on quality of care for acute myocardial infarction: a randomized controlled trial. JAMA 1998;279:1358-63.

9 Mehta RH, Montoye CK, Gallogly M, et al. Improving quality of care for acute myocardial infarction: the guidelines applied in practice (GAP) initiative. JAMA 2002;287:1269-76.

10 Eagle KA, Montoye CK, Riba AL, et al. Guideline-based standardized care is associated with substantially lower mortality in medicare patients with acute myocardial infarction: the American College of Cardiology's guidelines applied in practice (GAP) projects in Michigan. J Am Coll Cardiol 2005:46:1242-8.

11 Graham JJ, Timmis A, Cooper J, et al. Impact of the National Service Framework for coronary heart disease on treatment and outcome of patients with acute coronary syndromes. Heart 2006;92:301-6.

12 Epstein AM, Lee TH, Hamel MB. Paying physicians for high-quality care. N Engl J Med 2004;350:406-10.

13 Moscucci M, Eagle KA, Share D, et al. Public reporting and case selection for percutaneous coronary interventions: an analysis from two large multicenter percutaneous coronary intervention databases. J Am Coll Cardiol 2005:45:1759-65.

14 Omoigui NA, Miller DP, Brown KJ, et al. Outmigration for coronary bypass surgery in an era of public dissemination of clinical outcomes. Circulation 1996;93:27-33.

15 Mittman BS. Creating the evidence base for quality improvement collaboratives. Ann Intern Med 2004; 140:897-901.

16 Moscucci M, Share D, Kline-Rogers E, et al. The Blue Cross Blue Shield of Michigan Cardiovascular Consortium (BMC2) collaborative quality improvement initiative in percutaneous coronary interventions. J Interv Cardiol 2002;15:381-6.

\section{STAMPS IN CARDIOLOGY}

\section{Diabetes}

T he Dominican Republic stamp was issued in association with the $7^{\text {th }}$ Latin American Congress for Diabetes held in 1989. The main design of the stamp features diabetic complications with a compilation of the heart, eye, kidney, and brain superimposed on an outline map of the country.

M K Davies A Hollman

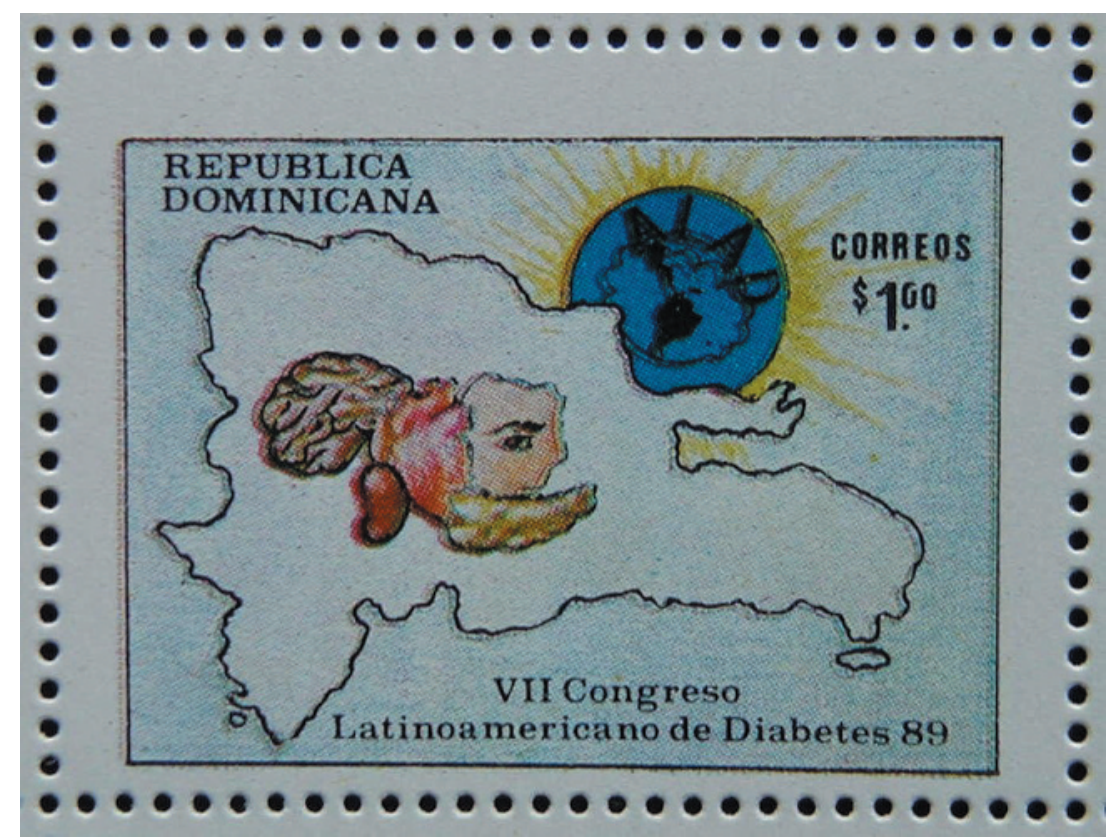

